\title{
ICANN: TRANSFORMATION OF APPROACH TOWARDS INTERNET GOVERNANCE
}

\author{
by
}

VERONIKA ŽOLNERČÍKOVÁ*

\begin{abstract}
Internet Corporation for Assigned Names and Numbers (ICANN) is one of the world's prior organizations governing the Internet. Since its establishement in 1998 it faced criticism concerning the lack of legitimacy and accountability. ICANN was also challenged because of the ongoing tight relationship with the US government, which was not considered to be acceptable by the rest of the world. The article focuses on the development of ICANN and its approach towards the criticism. It elaborates on the sector-specific issues regarding Internet governance. And finally it informs the reader about the process of transformation of ICANN, which severed the link between the US government and ICANN.
\end{abstract}

\section{KEY WORDS}

ICANN, Internet Governance, Self-regulation, Internet, Domain

\section{INTRODUCTION}

The year 2016 was a year of change when it comes to Internet governance. It is to be remembered as the year when the debate over the prevailing substantial influence of US on the management of the Internet escalated. After numerous debates on the subject in the last two decades, a shift forward to more neutral and independent Internet governance was taken. The final step was executed in September 2016, when the newspaper stated that the former president of the US, Barack Obama, had given away the Internet. That is obviously a rather simplified statement. The Internet is an intangible object, a network incapable of being a tradable property and as such cannot be handed over. What happened from a legal viewpoint

v.zolnercikova@gmail.com, Veronika Žolnerčíková is a student of Charles University in Prague, Faculty of Law, Czech Republic. 
in autumn 2016 is that the contract allowing US to oversee one of the critical functions of the Internet Corporation for Assigned Names Numbers (ICANN), an industry regulator with much power, has expired.

The focus of this article lies in ICANN, what ICANN is and why it is an important entity in the field. This paper will clarify what its day-to-day tasks are and what are the concerns related to its neutrality and accountability since it was established. Lastly, it will offer a summary of recent development of Internet governance regarding ICAN.

\subsection{INTERNET CORPORATION FOR ASSIGNED NAMES AND NUMBERS}

ICANN is an organization based in United States and created as an industry regulator of the Domain Name System (DNS). DNS is sometimes called the "Internet address book"; its core function is to translate IP addresses into more meaningful form from the viewpoint of an Internet user. An IP address consists of string of numbers (IPv4) or numbers and letters (IPv6) designating the access point in a network. The point of origin or termination is a certain device, for example, a computer. An IP address serves as a label for that device and allows other devices its localization and connectivity. ${ }^{1}$ There are two IP standards, IPv4, which is widely used at present, and its possible replacement, IPv6. The stock of IPv4 addresses had soon run low, and they had become a rare commodity. The stock was exhausted in 2011 . $^{2}$ That is a reason for implementation of IPv6. The new Internet protocol offers an inexhaustible number of combinations for the foreseeable future. ${ }^{3}$

However, IP addresses are hard to remember. That is why DNS translates these addresses into what we know as domain names, such as "google.com". It is unnecessary for the user to know the precise address and location of the device containing the desirable content. And the provider of the content wants its content accessible as easily as possible. This is why the provider aims to obtaIn an easily memorable

\footnotetext{
Mueller, M. L. (2010) Networks and states: the global politics of Internet governance, MIT Press. p. 230; Bygrave, L. A. \& Bing, J. (2009) Internet governance: Infrastructure and institutions, Oxford University Press, pp. 147-150.

2 The so-called free pool stock of IPv4 addresses assigned directly by the Internet Assigned Numbers Authority to regional internet registries. Source: 2011. Free Pool of IPv4 Address Space Depleted. [online] Available from: https://www.nro.net/ipv4-free-pool-depleted/ [Accessed 10 May 2017].

3 What is Ipv6? [online] Available from: https://www.apnic.net/community/ipv6/ [Accessed 10 May 2017].
} 
domain name. As the full name of ICANN suggests, it plays a key role in the allocation of domain names.

If we look at the mentioned domain name "google.com", we can see a toplevel domain name (TLD). TLDs can be either generic (.com, net, .gov, .edu) or country specific (.cz, .uk, .at, .no). The first are designated as gTLDs, the second as ccTLDs. ${ }^{4}$ It is within the powers of ICANN to establish what is and what is not a gTLD and grant or not grant a ccTLD. ${ }^{5}$ Although it may seem that there cannot be much dispute when it comes to ccTLDs, issues may arise when it comes to countries or parts of countries that seek independence but are not recognized world-wide. ${ }^{6}$

The mappings between domain names, TLDs and IP addresses are contained in a plain text file called the root zone file.

"The root zone file is the master definition for the DNS and contains the authoritative list of top-level domains and the information needed to find the authoritative domain name servers for each domain name. ${ }^{\prime 7}$

Although ICANN is the regulator and coordinates the content of the root zone file, the file is housed by a private non-profit company called VeriSign. In 2000, VeriSign acquired a company called Network Solutions, Inc., a government contractor, who had in a fact a monopoly granted by the US, since it was the only registrar for domain names. By doing so for an initial fee and a yearly fee, the company made a fortune. The contract with the US and all its perks succeeded to VeriSign. ${ }^{8}$

\subsection{ICANN AS THE GOVERNOR}

ICANN governs multiple key elements of the Internet necessary for its function, either directly or through multiple associated or supporting organizations. Among these some have been formally delegated by ICANN and some can be controlled by ICANN factually. Here is a summary: ICANN a) manages the IP address spaces, b) assigns addresses to regional registries, c) creates and assigns TLDs, d) maintains the root name servers,

4 Bygrave, L. A. \& Bing, J. (2009) Internet governance: Infrastructure and institutions, Oxford University Press, p. 163.

5 Ibid., pp. 147-148.

6 For example, a gTLD (not a ccTLD) .cat was created for the Catalonian community in Spain.

7 1987. Domain names: implementation and specification. [online] Available from: http://www. ietf.org/rfc/rfc1035.txt [Accessed 14 January 2017].

8 Koppell, J. G. (2005) Pathologies of accountability: ICANN and the challenge of "multiple accountabilities disorder". Public Administration Review, 65, 94-108, p. 101. 
e) maintains registries of IP identifiers, and f) adopts Internet policies and standards. ${ }^{9}$

That is why ICANN is considered to be one of the world's main organizations governing the Internet. The legitimacy to govern Internet is not bound to one jurisdiction; it is neither derived from any of the established international organizations nor is it granted to one specific entity. Internet governance is a complex concept being executed by multiple bodies with unclear hierarchy and usually unclear legitimacy as well. The model of Internet governance will be discussed in more depth later. Nevertheless, a working definition is needed to clarify what I am referring to when I discuss Internet governance. For these purposes, I will use the definition that can be found in a report from 2005 by the Working Group on Internet Governance, ${ }^{10}$ which goes as follows:

"Internet Governance is the development and application by governments, the private sector and civil society, in their respective role, decision-making procedures, and programmes that shape the evolution and use of the Internet. "11

\subsection{CHALLENGES OF INTERNET GOVERNANCE}

Because of the rather special nature of the Internet, a need for more flexible organizations is arising. ICANN is a new type of organization that is tied deeply to the private sector, yet it has the unprecedented power to implement a set of rules, which will then be followed all around the world. National regulation has only a limited effect on discourse nowadays, as the Internet is the first man-made invention that is truly transnational.

The legitimacy of an internationally recognized organization should derive from sovereign nations, which will then be bound by the measures adopted by that organization. But the legitimacy derived only from the US, and the relationship with the US faced criticism from other countries. ${ }^{12}$

For detailed description of ICANN's functions, I recommend Chapter 3 of BYGRAVE, L. A. \& BING, J. 2009. Internet governance: Infrastructure and institutions, Oxford University Press.

10 Working Group on Internet Governance (WGIG) was initiated by the United Nations after the World Summit on Information Society in 2003 as a response to a debate concerning what Internet governance is and what are the respective roles of governements, international organizations etc. in the Internet field.

11 2005. Report of the Working Group on Internet Governance. [online] Available from: http:// www.wgig.org/docs/WGIGREPORT.pdf [Accessed 12 February 2016]. 
There is an effort to sever the bond since ICANN's standards became recognized world-wide.

ICANN is an organization that was raised from the bottom up. It was never officially established as a standard setting body; its beginning was merely a group of people dealing with the technicalities of the Internet. And eventually their task became more complex along with their powers.

Therefore, the legitimacy of the establishment of ICANN was contested multiple times. ${ }^{13}$ The relationship with the US was one of the core problems since its establishment, but not the only one. Another reoccurring issue is the paucity of legislation defining the scope of ICANN's powers, which the international community would prefer to control ICANN somehow. ICANN is limited only by memorandums and affirmations that are not enforceable. ICANN is constricted by numerous contracts as well, but again, with the US. There are no means of control beyond US borders.

The reason why its limited accountability should make the Internet community nervous, is because ICANN is a policy maker and at the same time maintains exhaustible resources. There is a discussion within United Nations about perceiving Internet access as a fundamental human right, ${ }^{14}$ yet the resources essential for it are limited and subject to trade. Therefore, ICANN is an organization that is a public rule-maker and a private company with customer oriented approach at the same time. Those two do not go well together. However, there is not much of a dispute when it comes to efficiency of ICANN.

\section{MODEL OF INTERNET GOVERNANCE}

ICANN is a non-profit public benefit corporation that was registered in California in 1998. It is a corporation with no public authority, its autonomy gained through numerous contracts. ${ }^{15}$ There are (at least) two reasons for the fact that one of the major governors of the Internet is a private corporation set up in one state. The first reason is that the Internet

${ }_{12}$ Mueller, M. L. (2010) Networks and states: the global politics of Internet governance, Mit Press, p. 64.

13 See Chapter 4 in Bygrave, L. A. (2015) Internet Governance by Contract, Oxford University Press.

14 2016. Draft resolution on the promotion, protection and enjoyment of human rights on the Internet. [online] Available from: ap.ohchr.org/documents/E/HRC/d_res_dec/A_HRC_32_L20.docx [Accessed 10 May 2017].

15 Bygrave, L. A. \& Bing, J. (2009) Internet governance: Infrastructure and institutions, Oxford University Press, p. 112. 
was originally a US invention and as such it was managed by US organizations. The second reason is that ICANN and associated bodies were created with the sole goal to manage the technical issues related with the Internet. ${ }^{16}$ The unique controlling position of the US made sense at the time, when all of the Internet users were located in the US and perhaps a few other countries, but not since the Internet became a global phenomenon. ${ }^{17}$

ICANN's primary goal is to edit the root zone file: in other words, to manage the DNS. Having an organization with this function is critical for the existence of the Internet. Before ICANN was established, the Internet was viewed as a free, self-governing, politically neutral entity. It was not until later that ICANN took over other tasks as well and became a centralized body controlling the Internet. This transformation was criticized by the public. ${ }^{18}$

\subsection{ESTABLISHMENT OF ICANN}

ICANN was not built in a day. Its main goal, to control the DNS, was originally managed by the Internet Assigned Numbers Authority (IANA). It was upon IANA to decide which domains would be marked as TLDs (top level domains, such as .com) and how a domain name could be registered. The first public reference acknowledging IANA's existence can be found in a memo considering Internet protocol standards from 1988. The significance of the root file was yet to be discovered, hence there was no public scrutiny concerning IANA's establishment and who was in charge. It was one Jon Postel, a UCLA ${ }^{19}$ graduate student, working in the Information Science Institute, who was enlisted as an IANA contact in the memo.

Jon Postel's task was to coordinate the Internet protocol and assign IP numbers and domain names. Therefore, it was solely in his hands, as the head of the department, to decide which TLDs would be created. He was also personally registering domain names. ${ }^{20}$

\footnotetext{
16 More on establishment of ICANN in Mueller, M. (2002) Ruling the root: Internet governance and the taming of cyberspace, MIT Press.

17 Froomkin, A. M. (2011) Almost Free: an Analysis of ICANN's 'Affirmation of Commitments'. Journal of Telecommunications and High Technology Law, 9, p. 194.

18 Mueller, M. L. (2010) Networks and states: the global politics of Internet governance, MIT Press, p. 64.

19 The University of California in Los Angeles.
} 
In these days, IANA was working on consensus based procedures, when it came to adoption of Internet standards. This pleased the Internet community, however the situation changed once the US Government gained more control over IANA. Under a series of contracts, control passed to The US Department of Commerce. ${ }^{21}$ A wave of criticism followed. An important question was raised. Is any government entitled to legitimize an organization governing a world-wide rare resource, and if so, why is it only one government on its own $?^{22}$ The response of the US was to privatize IANA by creating ICANN, a private company, which officially took control over IANA's functions in $1999^{23}$ when the government's contracts expired.

\subsection{SELF-REGULATING INDUSTRY}

There is not one central body governing the Internet. ${ }^{24}$ The task is spread amongst multiple bodies with various backgrounds, and ICANN is just one of them. Whereas the opinions on the efficiency of this system differ, the validity of delegation of power to these bodies is widely deemed questionable; the same goes for their accountability.

On the basis of a closer look into this industry, it can be said that legitimacy issues are a sector specific problem. ${ }^{25}$ Most of the governing bodies were raised from the bottom-up, and they were not formed with the purpose to adopt rules. Their focus lies on the technicalities; they were established to deal with the functions of the Internet, not with rulemaking. However, in this industry, resolving of technical issues goes hand in hand with setting binding standards. As a user of the Internet, you cannot freely decide not to follow these standards, not because you can be legally punished for it, but because you will be disconnected from the network (except for those parts which follow the same standard as you do). Alternative standards do exist, but only one standard is accepted globally.

20 More on conduct of ICANN during the early days and Jon Postel's role can be found in Mueller, M. (2002) Ruling the root: Internet governance and the taming of cyberspace, MIT Press. Bygrave, L. A. \& Bing, J. (2009) Internet governance: Infrastructure and institutions, Oxford University Press.

21 Froomkin, A. M. (2003) Habermas@ discourse. net: Toward a critical theory of cyberspace. Harvard Law Review, 116, 749-873., pp. $840-841$.

22 Ibid., p. 94.

23 Bygrave, L. A. \& Bing, J. (2009) Internet governance: Infrastructure and institutions, Oxford University Press, p. 102.

24 Ibid., p. 92.

25 See also Bonnici, J. P. M. (2008) Self-regulation in cyberspace, Cambridge University Press. 
Another thing that resulted from the rather uncommon nature of these governing bodies is that their roots lie originally in research facilities. Also, these facilities were connected with the US government, since the US is the place where the project unwound. In the beginning, the Internet was just a project; it was not until later that its significance exceeded US borders. Thereafter, the people working on the development of the Internet, engineers and researchers, continued working in those bodies and adopted decisions even after their significance expanded.

That is how this so-called self-regulating industry emerged. One of the characteristics of self-regulation is that the rules are adopted by those who are taking part in the activity. The main advantage of this system of regulation is that it is more flexible. ${ }^{26}$ It allows skipping the middle man. If you are a part of that industry, you have the best notion of what is needed. You are the expert and the rule-maker at the same time.

One of the examples of such organization is IETF, the Internet Engineering Task Force. ICANN is considered to be a self-regulatory body as well, but with one exception: there is a state intervening in its affairs. ${ }^{27}$ That is generally considered to be a disqualification for a self-regulating organization. But, as stated earlier, ICANN is of a rather special nature and does not fit in any categories.

This system of self-regulation puts above all its ability to implement a wide variety of its member's interests into its policy. It is run by a group of people that are themselves vested in the subject matter and on the basis of their experiences adopt regulation concerning their common interest. This is called a semi-autonomous social field $(\mathrm{SASF})^{28}$, and the rules adopted in that field are binding for its members. On the one hand, if members adopt the rules themselves, they are more likely to be satisfied with them. On the other hand, are all of the affected parties truly present or just "most" of them? All interests should be represented equally, and if not, the effectively and legitimacy of that system can be doubted. ${ }^{29}$

\footnotetext{
Ibid., pp. 23-24.

Ibid., pp. 25-26.

Ibid., pp. 25-26.

Ibid., p. 102.
} 


\subsection{INTERNET ENGINEERING TASK FORCE AS A ROLE MODEL} IETF is another self-regulating organization operating on the Internet field. IETF deals with standard-setting processes; its first meeting, held in 1986, was attended by 21 US government officials. Since 1991, these meetings became open to non-governmental organizations as well, and later the organization became independent from the US government. ${ }^{30}$ That constitutes the biggest difference between IETF and ICANN.

IETF does not have regular members; it is made of volunteers. Meetings of IETF are open to all, and everyone can join its mailing list and help develop Internet standards. Everyone, without discrimination, has a say. When ICANN was formed it sought to enjoy the same source of legitimacy as IETF. ${ }^{31}$ ICANN considers IETF to be an exemplary model of what a selfgoverning multistakeholder organization should look like. ${ }^{32}$ What is a stakeholder? A person, group or organization that has vested its interest or stake in organizations like ICANN or IETF because it is capable of affecting the organization or/and being affected by it. ${ }^{33}$ Therefore, a multistakeholder organization is such an organization that allows multiple entities to influence its decisions.

Following IETF's model, ICANN also opened the discussion for volunteers, and its meetings are public. However, it is facing critique for making it hard for an ordinary user to be truly heard. Unlike IETF, ICANN does not discuss its matters on the Internet; therefore one must attend meetings of ICANN, which take place all around the world.

Furthermore, IETF is a standard setting body, whereas ICANN is a body governing a rare resource with the potential to affect competition by its actions. It manages a public resource on one hand; on the other, it is a private company capable of generating profit and has a customer driven approach as well.

${ }^{30}$ Internet Engineering Task Force. [online] Available from: https://en.wikipedia.org/wiki/ Internet_Engineering_Task_Force [Accessed 14 December 2016].

31 Froomkin, A. M. (2003) Habermas@ discourse. net: Toward a critical theory of cyberspace. Harvard Law Review, 116, 749-873., pp. $842-843$.

32 Ibid., pp. $843-844$.

33 2014. Cross Community Working Group (CCWG) Charter. [online] Available from: https:// www.icann.org/news/announcement-2014-11-05-en [Accessed 14 January 2017], p. 2. 


\section{ACCOUNTABILITY}

Even though ICANN is one of few organizations operating in the field of Internet governance, and we already established that the nature of all of these organizations is uncommon, ICANN faced criticism the most. ICANN chose to apply the multistakeholder model the same as IETF, but it did not treat all of the voices alike. So, unlike IETF, it did not have the public behind all of its actions. It did not have international support either, since the only sovereign capable of controlling ICANN was the US. And the US itself was step by step losing control over ICANN, although for a good reason: to satisfy other countries and to support the idea of truly independent organization.

As a result, ICANN was repetitively accused of being unaccountable. ${ }^{34}$ But to whom should be ICANN accountable? And what do we mean, when we talk about ",accountability“?

\subsection{FIVE DIMENSIONS OF ACCOUNTABILITY}

In 2005, an article discussing ICANN accountability was written by Jonathan GS Koppell. The mentioned article is called "Pathologies of Accountability: ICANN and the Challenge of 'Multiple Accountabilities Disorder'". ${ }^{35}$ Accountability in Koppell's perspective reflects one's understanding of the place of bureaucracy in a democratic state. ${ }^{36}$ Those who exercise power are bound to exercise it within external means and internal norms. Therefore, they are accountable for performing their actions within these borders. But each individual is accountable by different means, to different entities and with different consequences arising from the breach of these constraints. That is why Koppell states that it is unfortunate to use one word to describe several conditions, which may or may not be found all together.

Koppell then describes five dimensions of accountability that are generally referred to when talking about accountability. The typology is

${ }^{34}$ See Chapter 4 in Bygrave, L. A. (2015) Internet Governance by Contract, Oxford University Press.

35 Koppell's article includes case study of ICANN and it shows very well the problem it is dealing with. ICANN accountability is suffering from something that Koppell describes as "multiple accountabilities disorder". It will serve to our purpose of defining accountability within ICANN well; nevertheless, keep in mind, that some of the issues with ICANN mentioned in Koppell's article itself are already resolved.

${ }^{36}$ Koppell, J. G. (2005) Pathologies of accountability: ICANN and the challenge of "multiple accountabilities disorder". Public Administration Review, 65, 94-108, p. 94. 
as follows: an organization is 1) transparent, when it reveals facts about its performance, 2) liable when it faces the consequences of its actions, 3) controllable, if it follows the orders of a principal, 4) responsible, if it follows the rules and 5) responsive, when it is able to fulfil the demands. ${ }^{37}$

Koppell further elaborates on the typology. He stresses that transparency is an important instrument for assessing a company's performance, since transparent organizations explain or account for their actions and therefore admit mistakes and do not avoid scrutiny. ${ }^{38}$

Liability follows transparency. An entity is liable when it faces the consequences of its actions, is punished for unlawful behaviour or is rewarded for success. In the public sector, it relates to elected officials, who can be punished by removal from their office. For example, judges are not liable in this sense. In the private sector, managers are rewarded on the basis of their performance. ${ }^{39}$

Controllability requires the existence of another entity that has the power to induce behaviour on an organization, resulting in accountability of that organization to the controlling entity. The organization is constrained by the commands of the principal. ${ }^{40}$

On the other hand, if the actions of the organization are bound by laws, rules and norms (including professional standards, company policies), not by commands, we talk about responsibility. ${ }^{41}$

Finally, we have responsiveness, which is contrary to controllability and responsibility, a horizontal type of accountability. A company is responsive when its policy has a customer-oriented approach and when its attention focuses on the needs of its constituents. ${ }^{42}$

\subsection{ICANN AND MULTIPLE ACCOUNTIBILITIES DISORDER}

ICANN is an organization which was first established as a controllable organization, acting on the behalf of the US Government. The US is its superior, which must be satisfied with the actions of ICANN. However, its goal is to satisfy different groups of actors on the Internet field as well (for example, potential owners of TLDs, constituents). That further

\footnotetext{
Ibid., p. 96.

Ibid., p. 96.

Ibid., p. 96-97.

Ibid., pp. 97-98.

41 Ibid., p. 98.

42 Ibid., pp. 98-99.
} 
establishes accountability in the means of responsiveness. ICANN itself desires to be responsive, to act on the basis of the needs of the community, but this notion sometimes clashes with other responsibilities of ICANN. ICANN's biggest struggle is with responsibility, since it failed to follow its own procedural norms repeatedly in the past, even to the extent that its elected officials were publicly criticizing the approach. ${ }^{43}$

When an organization fails to satisfy some of these different notions of accountability, it is simply marked as non-accountable. The different meanings of the term are ignored, as Koppell states in his article. Hence, if one focuses on responsibility, let's say, s/he would label ICANN as nonaccountable, even though it would satisfy the criteria for responsiveness. This creates pressure on the organization. Every entity should be by design accountable only in the sense that is necessary for its proper function.

Those organizations, which behave on the basis of incentives from multiple entities, then suffer from something Koppell calls the "multiple accountabilities disorder", in other words the "MAD" problem. Such organization is expected to be accountable in every sense, and that is a challenge, if not impossible. The organization will sometimes emphasize the directives of principals, while at other times trying to focus on customers. In the long run, everyone is displeased. ${ }^{44}$

\section{TRANSFORMATION OF ICANN}

ICANN was always aware of the problem with its unclear accountability. The US thought that the creation of ICANN as a private corporation will soothe the critics of the on-going oversight of US Government over the Internet. But even after the transformation of IANA functions to ICANN, contracts with the Department of Commerce were still intact. ICANN dealt with the problem by multiple means, but the biggest changes came in three steps, the first of which was the Affirmation of Commitments from 2009, revisiting the ICANN-US relationship, followed by the creation of Cross Community Working Group in 2014 preparing the final departure of ICANN from the US government and dealing with accountability issues, finalized in 2016 by the IANA transition. As you can see, the major changes

${ }^{43}$ Froomkin, A. M. (2003) Habermas@ discourse. net: Toward a critical theory of cyberspace. Harvard Law Review, 116, pp. 749-873.

44 Koppell, J. G. (2005) Pathologies of accountability: ICANN and the challenge of "multiple accountabilities disorder". Public Administration Review, 65, 94-108, p. 99. 
have been made just recently, and it is still too early to say if they served their purpose.

\subsection{AFFIRMATION OF COMMITMENTS}

On September 30, 2009, the US Department of Commerce signed an Affirmation of Commitments with ICANN to review their relationship. The ICANN CEO states that ICANN remains a private non-profit organization, not under control of a single entity and reviewed by public scrutiny. ${ }^{45}$ The US relationship with ICANN was maintained through a series of contracts, the most important of which is the Memorandum of Understanding, which later transitioned into the Joint Project Agreement (2008) and the IANA contract. ${ }^{46}$

As the IANA contract was about to expire in 2011, there was a hope for ICANN to gain more independence. However, the Affirmation of Commitments does not cover the future of the IANA contract at all, resulting in doubt that an actual change will happen. Still, the Affirmation grants ICANN more independence, and it is clear that the US Government is willing to address the critique for not letting ICANN be free. This is proven by the commitment of the US not to prolong the Joint Project Agreement, as is stated in the first paragraph of the Affirmation. ${ }^{47}$

The rest of the stipulations not to interfere with ICANN tasks made by the Department of Commerce, even though promising, are not to be taken for granted. There is no enforceability of such statements.

\subsection{CROSS-COMMUNITY WORKING GROUP}

Enhancing ICANN accountability became the primary goal of the ICANN community. In 2014, an intention to evaluate ICANN accountability was laid down, and for that purpose a Cross-Community Working Group on Enhancing ICANN Accountability (herein after "CCWG") was created. All the criticism on ICANN during its short existence made clear that ICANN needs to review its accountability standards to satisfy its constituents.

The promises in the Affirmation of Commitments were held after all, and the US Government let the Joint Project Agreement expire. New

45 Froomkin, A. M. (2011) Almost Free: an Analysis of ICANN's 'Affirmation of Commitments'. Journal of Telecommunications and High Technology Law, 9, p. 188.

46 Ibid., p. 192.

47 Ibid., p. 198. 
revision mechanisms were needed to compensate for the loss of the principal. ${ }^{48}$ Since the IANA contract was prolonged only for it to expire in 2016 instead of 2011, another important matter was to be discussed.

Unfortunately, the first ICANN proposal to create a revisory body was not met pleasantly by the public. A community driven change was demanded. A CCWG was formed as a result of meeting convened by the board in Los Angeles. ${ }^{49}$ The CCWG was established as a body that was proposed by the multistakeholder community, to be run by the community, and accessible to anyone willing to contribute. ${ }^{50}$

The CCWG has two goals, represented by two separate work streams. One is to propose solutions for enhancing ICANN's accountability within the time frame of IANA transition. The second goal is to focus on addressing accountability topics unrelated to The transition that can be implemented after the transition. ${ }^{51}$

\subsection{NEW BYLAWS}

The first proposal by the CCWG was drafted in May 2015. ${ }^{52}$ It proposes to amend the bylaws of ICANN to specify what ICANN does - not changing it, just clarifying. New revisory mechanisms should be adopted to control that ICANN stays within the limits of the bylaws and the purpose stated therein. This Independent Review Process will be granted powers to reject or approve changes to the bylaws, reject proposals (budget, operating and strategic plans), remove a member of the board or to recall the entire board. The goal of this provision is to be able to resolve a situation when there is an impasse in finding a consensus. ${ }^{53}$

New bylaws were adopted on May 27, 2016 as a result of the CCWG efforts. Article III of the bylaws is dealing with Transparency, and Article IV is designated to Accountability and Review. ${ }^{54}$ The bylaws propose to enhance transparency by the pledge to make information on its tasks

\footnotetext{
48 ICANN accountability. [online] Available from: https://icannwiki.com/ICANN Accountability [Accessed 5 December 2016].

49 Ibid.

50 The working progress can be observed and the effort joined here: https://community.icann. org/display/acctcrosscomm/WS1+-+Enhancing+ICANN+Accountability.

51 2014. Cross Community Working Group (CCWG) Charter. [online] Available from: https:// www.icann.org/news/announcement-2014-11-05-en [Accessed 14 January 2017], p. 2.

52 ICANN accountability. [online] Available from: https://icannwiki.com/ICANN_ Accountability [Accessed 5 December 2016].

53 Ibid.
} 
and meetings publicly available and for that purpose adopt a new Documentary Information Disclosure Policy and Independent Review proceedings.

Revised accountability mechanisms include the following instruments:

- Reconsideration Process, which allows those materially affected by ICANN decisions to request a reconsideration of that action by the Board;

- Independent Review Process, which allows those eligible to request Reconsideration Process to request also a review by a third independent party, if ICANN performs an action that can be deemed to be in collision with the bylaws. The result of such Review is then published on the ICANN webpage.

- Ombudsman, which is an independent entity, who can evaluate the complaints of members of the ICANN community who are deemed to be treated unfairly by a member of ICANN staff, Board or constituent body. ${ }^{55}$

\subsection{IANA STEWARDSHIP TRANSITION}

In March 2014, the intent to hand over IANA functions to the global multistakeholder community was announced. Since that meant abandoning the historical contractual relationship with the US, the CCWG was also given the task to consider the impact of the transition on ICANN's accountability.

On October 10, 2016, the contract between IANA and the US Department of Commerce expired. ${ }^{56}$ Following a long process starting in $2014^{57}$ preparing the transition of IANA to the hands of the Internet global community, the cord between ICANN and the US Government, representing 20 years of development, was cut.

54 BYLAWS for INTERNET CORPORATION for ASSIGNED NAMES AND NUMBERS. [online] Available from: https://www.icann.org/resources/pages/bylaws-2016-02-16-en [Accessed 5 December 2016].

55 Accountability Mechanisms. [online] Available from: https://www.icann.org/resources/pages/ mechanisms-2014-03-20-en [Accessed 10 December 2016].

56 Stewardship of IANA Functions Transitions to Global Internet Community as Contract with U.S. Government Ends. [online] Available from: https://www.icann.org/news/announcement2016-10-01-en [Accessed 14 December 2016].

57 The process of the transition is available to public scrutiny here: https://www.icann.org/ resources/pages/transition-2014-03-23-en 
Regardless of how dramatically the "hand-over of the Internet" was perceived by media, from the viewpoint of an ordinary user, nothing changes. But those, who are interested in participating, can sign up to a newsletter and watch the progress online. ${ }^{58}$

\section{ICANN IN THE PRESENT}

As Koppell states, the MAD problem is bestowed upon those organizations that are trying to listen to commands from multiple sources. Therefore, it can be partially fixed by clarifying the goal of the organization and acting accordingly with the sole purpose of achieving that goal. The problem of ICANN was its need to respond to commands from above, as well as from the bottom. Since the cord to the US Government was recently cut, ICANN can now fully focus on satisfying the Internet community.

Nevertheless, keep in mind that the power to control an agency operating in a complex, technical area is always small, since a citizen's ability to make resolved judgment in the field is limited. ${ }^{59}$ Such a company will always have broader borders for its behaviour. Now, with the election process established for ICANN, there is at least a way to make the elected officials liable for their unsatisfying actions and to remove them from office. And with the US Government out of the picture, ICANN is now not divided between its principal and its constituents.

From 2014, when the preparation for the transition started, ICANN claims to be willing to hear out everyone who wants to participate, the same as its role model IETF does. The only difference between a member appointed by a chartering organization and an individual participant is that the unappointed participant cannot have a say in consensus call or a decision. ${ }^{60}$

Even after the transition, ICANN remains dependant on multiple contracts granting it its power. This organisation does not derive from traditional legislative bodies and is not governed by public international law. ${ }^{61}$ Criticism may not be the only result of ICANNs specific nature, as there are already judicial disputes over its legitimacy.

\footnotetext{
Sign up to a newsletter is available on https://icannwiki.com/

59 Koppell, J. G. (2005) Pathologies of accountability: ICANN and the challenge of "multiple accountabilities disorder". Public Administration Review, 65, 94-108, p. 97.

60 2014. Cross Community Working Group (CCWG) Charter. [online] Available from: https:// www.icann.org/news/announcement-2014-11-05-en [Accessed 14 January 2017], p. 5.

${ }_{61}$ See Chapter 4 in Bygrave, L. A. (2015) Internet Governance by Contract, Oxford University Press.
} 
In 2006, Danish Supreme Court dealt with the question, whereas the Memorandum of Understanding (later transformed in the Joint Project Agreement, as discussed above) signed between ICANN and US Department of Commerce gives ICANN the competence to manage .dk domains. The decision was, that it is indeed possible to constitute legal competence by delegation via contract. ${ }^{62}$

Similar issue concerning ICANN's power over area specific domains was raised in front of California Superior Court. The case revolved around the right to delegate the africa top level domain, a dispute between ICANN and DotConnectAfrica (DCA) originating in 2013. Both preliminary injunctions by DCA were dismissed so far. ${ }^{63}$

\section{CONCLUSION}

The transition of ICANN does not fix all its problems. Only a legal framework could amend the shortcomings with the responsibility dimension of accountability. So far, there are no legal requirements for ICANN. ICANN is trying to compensate for the lack of it by setting out its own behavioural norms and policies. Despite that, it can be expected that its unclear responsibility will remain a major issue for ICANN and will be challenged once more in the future.

\section{LIST OF REFERENCES}

[1] 1987. Domain names: implementation and specification. [online] Available from: http:// www.ietf.org/rfc/rfc1035.txt [Accessed 14 January 2017].

[2] 2005. Report of the Working Group on Internet Governance. [online] Available from: http://www.wgig.org/docs/WGIGREPORT.pdf [Accessed 12 February 2016].

[3] 2011. Free Pool of IPv4 Address Space Depleted. [online] Available from: https://www.nro. net/ipv4-free-pool-depleted/ [Accessed 10 May 2017].

[4] 2014. Cross Community Working Group (CCWG) Charter. [online] Available from: https:// www.icann.org/news/announcement-2014-11-05-en [Accessed 14 January 2017].

[5] 2016. Draft resolution on the promotion, protection and enjoyment of human rights on the Internet. [online] Available from: ap.ohchr.org/documents/E/HRC/d_res_dec/A_ HRC_32_L20.docx [Accessed 10 May 2017].

See Chapter 4 in ibid.

63 ICANN Free to Proceed with the Delegation of AFRICA Following Court Decision. [online] Available from: https://www.icann.org/news/announcement-3-2017-02-09-en [Accessed 15 May 2017]. 
[6] Accountability Mechanisms. [online] Available from: https://www.icann.org/resources/ pages/mechanisms-2014-03-20-en [Accessed 10 December 2016].

[7] Bonnici, J. P. M. (2008) Self-regulation in cyberspace, Cambridge University Press.

[8] Bygrave, L. A. \& Bing, J. (2009) Internet governance: Infrastructure and institutions, Oxford University Press.

[9] Bygrave, L. A. (2015) Internet Governance by Contract, Oxford University Press.

[10] BYLAWS for INTERNET CORPORATION for ASSIGNED NAMES AND NUMBERS. [online] Available from: https://www.icann.org/resources/pages/bylaws-2016-02-16-en [Accessed 5 December 2016].

[11] Froomkin, A. M. (2003) Habermas@ discourse. net: Toward a critical theory of cyberspace. Harvard Law Review, 116, pp. 749-873.

[12] Froomkin, A. M. (2011) Almost Free: an Analysis of ICANN's 'Affirmation of Commitments'. Journal of Telecommunications and High Technology Law, 9.

[13] ICANN accountability. [online] Available from: https://icannwiki.com/ICANN Accountability [Accessed 5 December 2016].

[14] ICANN Free to Proceed with the Delegation of.AFRICA Following Court Decision. [online] Available from: https://www.icann.org/news/announcement-3-2017-02-09-en [Accessed 15 May 2017].

[15] Internet Engineering Task Force. [online] Available from: https://en.wikipedia.org/wiki/ Internet_Engineering_Task_Force [Accessed 14 December 2016].

[16] Koppell, J. G. (2005) Pathologies of accountability: ICANN and the challenge of "multiple accountabilities disorder". Public Administration Review, 65, pp. 94-108.

[17] Mueller, M. (2002) Ruling the root: Internet governance and the taming of cyberspace, MIT Press.

[18] Mueller, M. L. (2010) Networks and states: the global politics of Internet governance, MIT Press.

[19] Stewardship of IANA Functions Transitions to Global Internet Community as Contract with U.S. Government Ends. [online] Available from: https://www.icann.org/news/ announcement-2016-10-01-en [Accessed 14 December 2016].

[20] What is Ipv6?. [online] Available from: https://www.apnic.net/community/ipv6/ [Accessed 10 May 2017]. 